\title{
Juvenile Kearns-Sayre syndrome initially misdiagnosed as a psychosomatic disorder
}

Søren Nørby, Patrick Lestienne, Isabelle Nelson, Inge-Merete Nielsen, Henning Schmalbruch, Ole Sjö, Mette Warburg

\begin{abstract}
We have investigated a 15 year old girl with progressive external ophthalmoplegia, including bilateral ptosis and retinal rod and cone cell dysfunction with atypical retinal pigmentation, complicated by cerebellar ataxia, partial cardiac conduction block, and diabetes mellitus. In infancy she had a severe crisis of bone marrow depression, and as a child she suffered from hypersensitivity to light, increasing fatigue, and vertigo, signs that were initially thought to be psychosomatic.

Histological examination showed mitochondrial myopathy, and subsequent mitochondrial DNA (mtDNA) analysis showed a deletion of approximately $\mathbf{5 5 0 0}$ base pairs in 35 to $40 \%$ of her muscle mtDNA. We therefore conclude that this patient has developed the Kearns-Sayre syndrome after a Pearson syndrome-like crisis in her first year of life.
\end{abstract}

Institute of Forensic Genetics, University of Copenhagen. Frederik V's Vej 11, DK-2100 Copenhagen, Denmark

$S$ Nørby

INSERM U 298, CHRU, Angers, France

P Lestienne

I Nelson

Department of Paediatrics, Sundby Hospital, Copenhagen, Denmark

I-M Nielsen

Institute of

Neurophysiology,

University of

Copenhagen,

Denmark

H Schmalbruch

Department of Ophthalmophysiology, Gentofte Hospital, Denmark

O Sjö

Department of Ophthalmology, Division of Paediatric Ophthalmology, Gentofte Hospital, Gentofte M Warburg

Correspondence to Dr Nørby

Received 6 April 1993 Revised version accepted for publication 3 August 1993
( $\mathcal{F}$ Med Genet 1994;31:45-50)

Kearns-Sayre syndrome (KSS) is a sporadic multisystem mitochondrial disorder with progressive external ophthalmoplegia, retinal dystrophy, and at least one of the following signs: heart block, cerebellar ataxia, and cerebrospinal fluid protein levels above $1 \mathrm{~g} / \mathrm{l}^{1-3} \mathrm{Rag}$ ged red fibres in the muscles are observed histologically and imply a mitochondrial disorder, which can be verified by electron microscopy and confirmed by mtDNA analysis. Onset is before 15 to 20 years of age and there is often growth retardation, delayed sexual maturation, and mental deterioration.

The retinal dystrophy in KSS and other cases with mitochondrial ophthalmoplegia features salt and pepper pigmentation in the fundus of some patients, in others there are black pigmented clumps. Electroretinography (ERG) shows cone dystrophy or both rod and cone dystrophy. ${ }^{4}$

Pearson syndrome (PS), also a mitochondrial disorder, presents with infantile sideroblastic pancytopenia requiring frequent transfusions, insufficiency of the pancreas, and hepatic dysfunction. ${ }^{56}$ Children surviving the pancytopenic crisis have been observed to develop progressive symptoms of $\mathrm{KSS}^{7-9}$ The aetiology of PS and KSS was not understood until partial deletions of mtDNA were observed in these patients. ${ }^{3610-14}$

We present here a new case of presumed PS developing into KSS and caused by an mtDNA deletion of 5491 base pairs. ${ }^{15}$

\section{Case report}

Pregnancy and delivery were unremarkable. There is no parental consanguinity and both parents and a brother are healthy. Birth weight was $3700 \mathrm{~g}$. At 5.5 months of age the patient had fever, anaemia, and blood in her stools. She also had leuco- and thrombocytopenia, the bone marrow was hypoplastic, and there was slight hepatomegaly. Explorative laparotomy showed nothing pathological. A number of blood transfusions were given over the next couple of years. The cause of the condition was presumed to be a cytomegalovirus (CMV) infection, as the CMV titre was high (132 decreasing to 16) and the virus was cultured from the urine.

Motor development was delayed. From the age of 3 years she was increasingly sensitive to light and preferred lying underneath the table at home. Ophthalmological examinations (elsewhere) gave no explanation and the cause of her troubles was thought to be psychological.

At school she had learning as well as behavioural problems and was referred to a psychologist and later a psychiatrist; eventually at 11 years she was transferred to a special class for children with learning disabilities. She moved slowly and never ran, and complained of weakness in the limbs, fatigue increased by exercise, and vertigo. At 12 years she fell off her bicycle twice and had four sudden unprovoked falls with unconsciousness for a few seconds. Atonic epileptic seizures were suspected. The EEG was paroxysmal, and for a short period she was treated with antiepileptic medicine (sodium valproate), which, however, was withdrawn because of serious side effects (severe hand tremor and ataxia). Retrospectively, these attacks could have been the result of heart conduction failure. She also developed increasing hearing impairment.

A cerebral CT scan showed symmetrical bilateral hypodense areas in the cerebellum. One year later a cerebral MRI scan confirmed symmetrical degeneration of the cerebellar white matter. In addition a hypodense area was seen in the left internal capsule.

Ophthalmological examinations were carried out by one of us (MW) over the age period 13 to 15 years. Overall consideration of the clinical findings then led to the diagnosis of Kearns-Sayre syndrome, which was subsequently supported by histological examination and eventually confirmed by mtDNA analysis. 


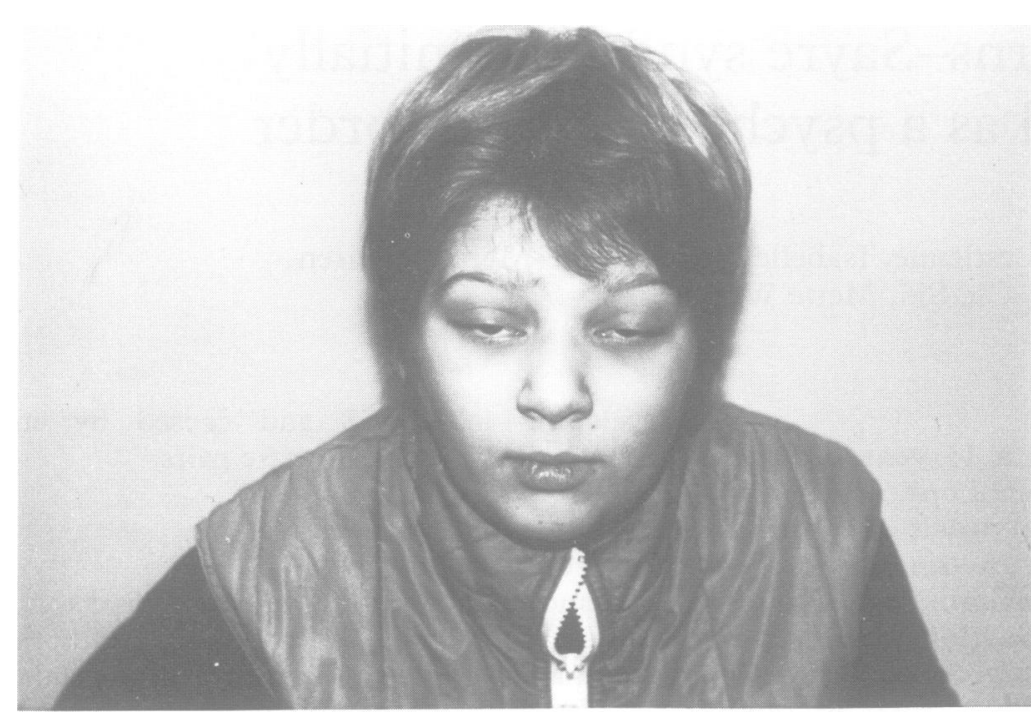

Figure 1 Facial features of the patient aged 15 years. Note the dark periorbital skin, ptosis, and hypotonia.

\section{CLINICAL EXAMINATION FROM 13 TO 16 YEARS} OF AGE

At the first examination the facial muscles were hypotonic with bilateral ptosis and a striking yellow-brown discoloration of the skin of the eyelids (fig 1). When the frontalis muscle was fixed she could raise the upper eyelids $2 \mathrm{~mm}$. The excursions of the external eye muscles were reduced: fusion horizontal -4 to +12 $P D$, vertical 2 PD. There was no ocular ataxia. There were no convergence movements and no squint. Stereopsis was present. Visual acuity was OD $6 / 6+2.25-1.75 \times\left(175^{\circ}\right)$, OS $6 / 6$ $+2.50-2.50 \times\left(120^{\circ}\right)$. Colour vision (AOHRR) was normal.

Direct and indirect ophthalmoscopy at 13 years showed parapapillary atrophy, attenuated arterioles, and abnormal reticular, macular, and peripheral pigmentation. Foveolar reflexes were absent.

A year later with fixation of the frontalis she could not raise her eyelids and other excursions were diminished. In the fundi small

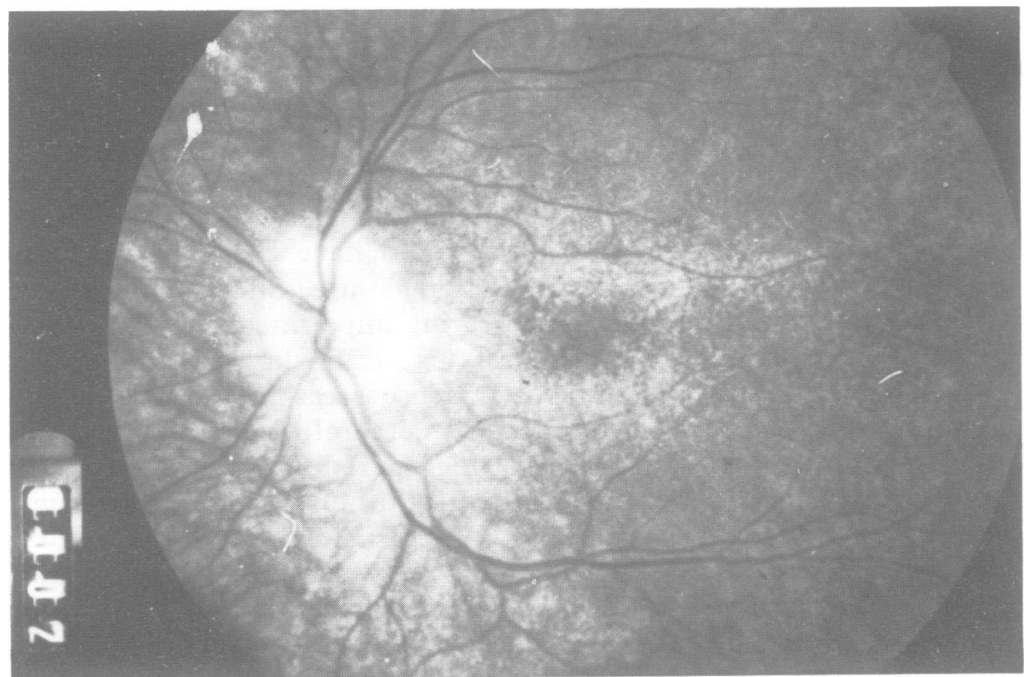

Figure 2 Very early fluorescence angiogram of the left eye. The macula has a mottled pigmentation. Further peripherally, the fundus shows a granular texture. The arterioles are narrow though not thread-like. Nasally the choroidal vessels can be seen through the retina, indicating mild degeneration of the retinal epithelium. clumps of dark pigmentation were beginning to appear in the inferior retina. At the latest examination the black pigmented clumps were dispersed all over the posterior pole of the fundus. Ophthalmoscopy was hampered by the patient's severe photoaversion.

Fluorescence angiography showed irregular atrophy of the retinal pigment epithelium (fig 2). Colour vision test (AO-HRR) showed a slight tritan defect.

Electroretinography (ERG) showed cone dystrophy at the age of 13 years, and one year later rod dystrophy was also present. Automatic perimetry was normal, but a Goldmann perimetry showed a concentric constriction to $30^{\circ}$. At 14 years campimetry $(3 / 1000$, white) showed a visual field of only $10^{\circ}$.

Electrocardiography at 14 years showed a left anterior hemiblock during rest with negative $T$ waves and ST depression during exercise. Progressive ataxia, dysarthria, and intention tremor were present, and she needed a wheelchair for outings with her family.

Pure tone audiometry indicated bilateral symmetrical sensorineural hearing loss with high frequency dominance; the speech reception threshold was $25 \mathrm{~dB}$ HL bilaterally. Tympanograms were normal. There was reduced cerebellar control of the eye movements but intact peripheral vestibular function on both sides.

Menarche was absent, but breast development had begun. Her stature was short, below the 3 rd centile for her age. At 16 years of age she developed insulin dependent diabetes.

\section{Materials and methods}

\section{HISTOLOGICAL EXAMINATION}

An open surgical biopsy was obtained under general anaesthesia from the medial vastus muscles. A sample was kept for histochemistry and frozen in a nitrogen slush. Cryostat sections $8 \mu \mathrm{m}$ thick were stained with haematoxylin and eosin, Gomori's trichrome stain, van Gieson stain, and for a battery of muscle enzymes. Other fibre bundles were kept at constant length and fixed and embedded for electron micrscopy; thin sections were stained with uranyl acetate and lead citrate. The diameters of 590 muscle fibres were measured in sections stained for adenosine triphosphatase.

\section{MITOCHONDRIAL DNA ANALYSIS}

\section{Isolation of DNA}

A part of the muscle biopsy was kept frozen at $-80^{\circ} \mathrm{C}$ in $10 \mathrm{mmol} / \mathrm{l}$ Tris- $\mathrm{HCl}, \mathrm{pH} \mathrm{8.0}$, $0.4 \mathrm{~mol} / 1 \mathrm{NaCl}, 2 \mathrm{mmol} / 1 \mathrm{EDTA}$ until DNA extraction. After thawing and addition of proteinase $\mathrm{K}$ and SDS (final concentrations of $200 \mu \mathrm{g} / \mathrm{ml}$ and $0.5 \%$ respectively), 30 to $50 \mathrm{mg}$ of tissue was homogenised, incubated overnight at $37^{\circ} \mathrm{C}$, and total DNA isolated by routine methods as previously reported. ${ }^{14}$

Southern blot analysis

Aliquots of $0.6 \mu \mathrm{g}$ total DNA were digested overnight with 10 units of BamHI, EcoRI, 
HindIII, PstI, PvuII, and SacI (Boehringer, Mannheim) respectively. After agarose gel electrophoresis $(0.8 \%$ BRL Ultrapure) and staining with ethidium bromide, the DNA fragments were blotted onto a Hybond $\mathrm{N}$ filter (Amersham), hybridised overnight to human mtDNA (100 ng), ${ }^{32} \mathrm{P}$ labelled by nick translation.

After washing using standard procedures ${ }^{16}$ and exposure to Fuji $x$ ray film at $-70^{\circ} \mathrm{C}$ using intensifying screens, an autoradiograph of the filter was developed. $\lambda$ DNA digested by EcoRI and HindIII was used as size marker. The percentage of $\mathrm{mtDNA}$ harbouring a deletion was estimated by computerised densitometry of the autoradiograph using the program IMAGE version 1.44 .

\section{Polymerase chain reaction}

Widely spaced primer (WISP) PCR $^{17}$ was performed as a supplement to Southern blotting, using 20 mer primers $\left(5^{\prime} \rightarrow 3^{\prime}\right)$ corresponding to the following mtDNA positions ${ }^{18}$ : $\mathrm{L}$ strand $8204 \rightarrow 8223$ (PL-1) and $H$ strand $14460 \rightarrow$ 14441 (PL-17). PCR conditions and subsequent analytical gel electrophoresis were as described previously, ${ }^{19}$ except that annealing was at $55^{\circ} \mathrm{C}$. The size marker was the same as in the Southern analysis. DNA samples from previously analysed patients with well characterised mtDNA deletions of $4977 \mathrm{bp}^{20}$ were included as controls.

DNA sequence analysis

Single stranded DNA sequence analysis was performed by dideoxynucleotide termination (Sequenase 2.0, US Biochemical Corporation), after asymmetrical amplification using $1 \mu \mathrm{g}$ target DNA and the primers PL- 1 and PL-17 in a ratio of 1:50. Sequence search and comparisons were performed with the help of Microgenie (Beckman) and with the Anderson sequence $^{18}$ as reference.

\section{Results}

HISTOLOGICAL EXAMINATION

Light microscopy showed moderately atrophic and hypertrophic fibres with diameters between $20 \mu \mathrm{m}$ and $65 \mu \mathrm{m}$ (mean diameter $38 \mu \mathrm{m}, \mathrm{SD} 19 \%$ ), and also an increased incidence of internal myonuclei. The muscle was not fibrotic and there was no evidence of muscle fibre necrosis or regeneration. Muscle fibres of different types formed a normal mosaic pattern; there were no signs of denervation. Type 1 fibres were slightly thicker than type 2 fibres (means $41 \mu \mathrm{m} v$ $35 \mu \mathrm{m})$.

Most fibres reacted for cytochrome c oxidase, but about $10 \%$ of the fibres were unstained. Sections stained with Gomori's trichrome stain showed about $1 \%$ of "raggedred" fibres. The same fibres displayed heavy deposits of blue formazan when stained for lactic acid dehydrogenase or succinate dehydrogenase. Under the electron microscope, subsarcolemmal aggregations of giant mitochondria and of mitochondria with paracrystalline inclusions were found (fig 3). Several intrafusal muscle fibres contained abnormal mitochondria as well, but the mitochondria in vascular smooth muscle cells were normal.

\section{MITOCHONDRIAL DNA ANALYSIS}

\section{Southern blot analysis}

The autoradiograph of the Southern blot is shown in fig 4. Digestion with BamHI and PvuII (fig 4, lanes 1 and 5 respectively) showed two populations of $\mathrm{mtDNA}$ molecules, one of which $(\Delta \mathrm{mtDNA})$ has a deletion of 5 to $6 \mathrm{~kb}$ ( $1 \mathrm{~kb}=1000$ base pairs) as compared to the normal one $(16.6 \mathrm{~kb})$. By densitometry the $\triangle \mathrm{mtDNA}$ was found to account for 35 to $40 \%$ of the total $\mathrm{mtDNA}$.

The presence of $\triangle \mathrm{mtDNA}$ also in the digests with HindIII, PstI, and SacI (fig 4, lanes 3, 4, and 6) shows that only one of the normally occurring two (SacI and PstI) or three (HindIII) sites for these enzymes remain in the $\triangle$ mtDNA molecule. For EcoRI (fig 4, lane 2)

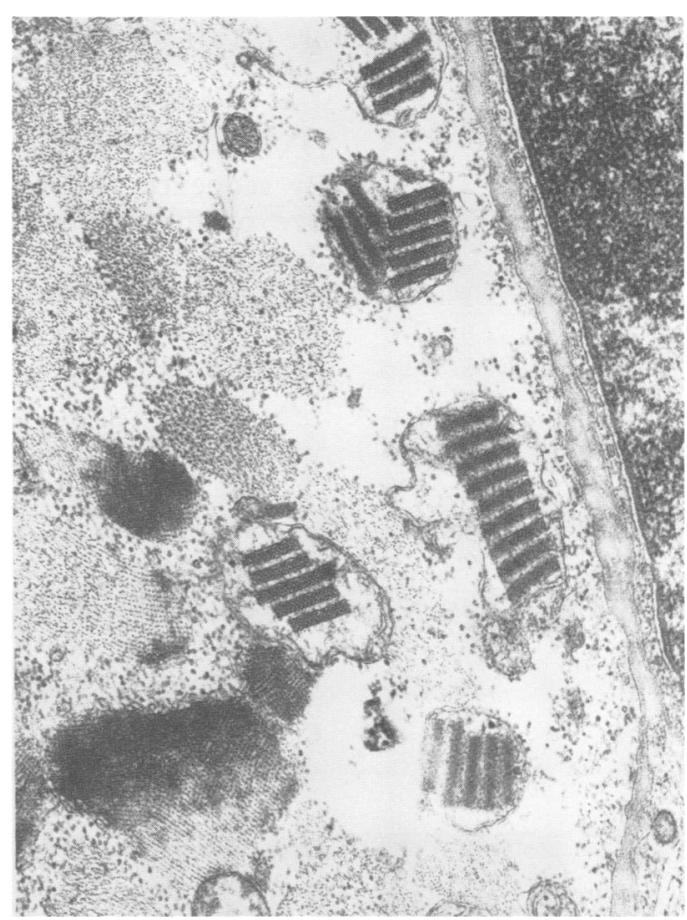

Figure 3 Electron micrograph of skeletal muscle showing ultrastructural mitochondrial changes, including the presence of paracrystalline bodies.

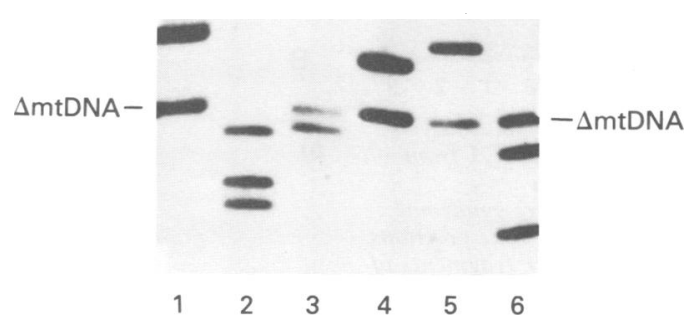

Figure 4 Autoradiograph of Southern blot of the patient's muscle mtDNA digested with the following enzymes: BamHI (lane 1), EcoRI (lane 2), HindIII (lane 3), PstI (lane 4), PvuII (lane 5), and SacI (lane 6). Fragments of less than $6 \mathrm{~kb}(1 \mathrm{~kb}=1000 \mathrm{bp})$ have been omitted from the photograph. $\Delta m \mathrm{mt} D A$ indicates the deletion molecule (size approximately $11 \mathrm{~kb})$. 
two sites are intact in the deletion molecule, since the largest fragment in that digest is about $1 \mathrm{~kb}$ smaller than $\triangle \mathrm{mtDNA}$.

Taken together these results show that the deletion which has produced the $\triangle \mathrm{mtDNA}$ molecule is 5 to $6 \mathrm{~kb}$ long and covers the following restriction site positions: 9020 (PstI), 9643 (SacI), 11680 and 12570 (HindIII), and 12640 (EcoRI), whereas neither of the flanking sites at positions 6910 (Pst I) or $14258($ Bam HI) are included.

\section{Polymerase chain reaction}

Fig 5 shows the PCR gel using the primer combination PL-1/PL-17. The controls, heteroplasmic for $\mathrm{mtDNA}$ with approximately $5 \mathrm{~kb}$ deletions, gave an amplification product of about $1.2 \mathrm{~kb}$ (lanes 1 and 2). Our patient's sample, however, gave a product of only about $0.8 \mathrm{~kb}$ (lane 3 ), showing that her deletion is approximately $0.4 \mathrm{~kb}$ larger than that of the controls. As expected, no amplification was observed from the coexisting wild type mtDNA, in which the primer target sequences are $6 \cdot 2 \mathrm{~kb}$ apart.

\section{DNA sequence analysis}

By sequence analysis the exact position and size of the deletion were defined, and the fusion point was identified as 8278/13 770 corresponding to a deletion of $5491 \mathrm{bp}$ (fig 6A). A closer look at the reference sequence, at both ends of and flanking the deletion, shows a doublet of $15 \mathrm{bp}$ (fig 6B), one copy of which is lost in the deletion process.

\section{Discussion}

Mutations in mtDNA have been found to cause a number of neuromuscular disorders and various other previously unexplained organ dysfunctions. ${ }^{21} 22$

A mutation can be present in all the patient's mtDNA molecules (homoplasmy) or in a certain percentage, coexisting with normal mtDNA (heteroplasmy). In the latter case the degree of heteroplasmy may vary from tissue to tissue ${ }^{92324}$ and with time, ${ }^{7}$ as well as from mother to child. ${ }^{25}{ }^{26}$ Heteroplasmy for a partial mtDNA deletion in skeletal muscle has been identified in KSS and other mitochondrial myopathies. ${ }^{9-11}$

Originally, KSS was considered to be a well defined clinical entity characterised by progressive external ophthalmoplegia (PEO), pigmentary retinopathy, and heart block, ${ }^{1}$ but more recent clinical evaluations of patients with PEO have shown that this myopathy can be associated with other clinical features as well, such as cerebellar dysfunction and raised cerebrospinal fluid protein, thus showing clinical heterogeneity of what has become known as the "ophthalmoplegia-plus" syndrome. $^{2}$

The nosological lumping of ophthalmoplegic patients with various degrees of additional

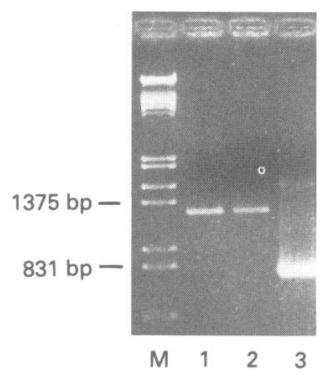

Figure 5 PCR analysis of muscle mtDNA from patients with Kearns-Sayre syndrome. $M=$ marker. The positions of the marker fragments of 831 and 1375 bp are 831 and $1375 \mathrm{bp}$ are
indicated. Lanes 1 and 2: indicated. Lanes 1 and patients with known deletion of $4977 \mathrm{bp}$ (the "common" deletion). Lane 3: amplified $m t D N A$ from the present patient.

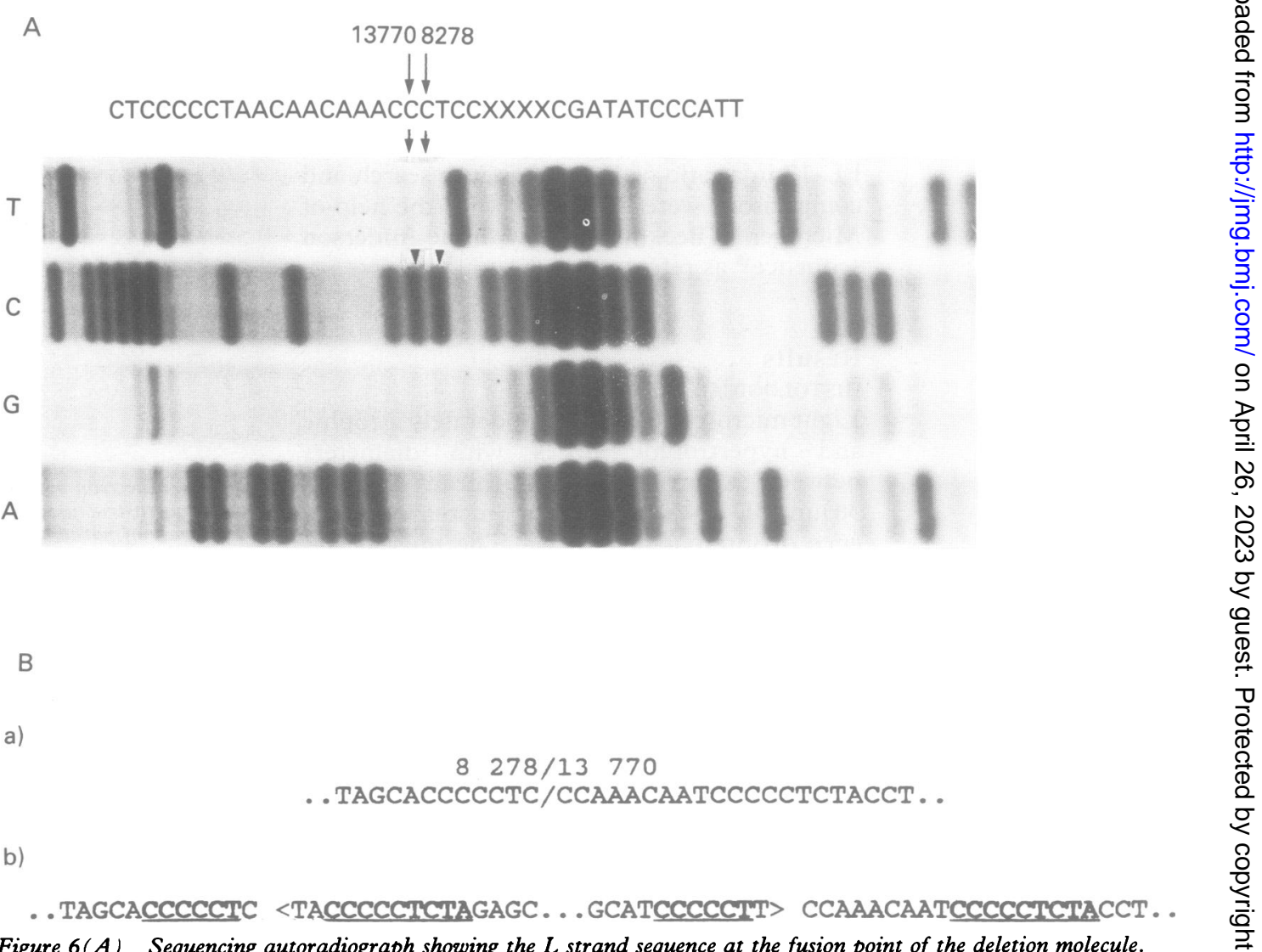

Figure 6(A) Sequencing autoradiograph showing the $L$ strand sequence at the fusion point of the deletion molecule. The numbers indicate the bases (arrows) which have been placed in juxtaposition by the deletion. (B) (a) The fusion sequence as derived from $(A)$ and the reference sequence..$^{18}(b)$ The wild type sequences in the two breakpoint regions of the deletion; ${ }^{18}$ repeats are shown in bold type and underlined. The deleted sequence is delineated by arrowheads. 
neuromuscular involvement has been justified through the finding of heteroplasmic mtDNA deletions in both classical KSS and uncomplicated ocular myopathy. ${ }^{31027}$

There is no correlation between size and location of the deletion in the mtDNA molecule and the phenotype of the patient; this can be explained by the observed general impairment of translation in mitochondria with an mtDNA deletion. ${ }^{928}$ The tRNA genes are "peppered" throughout the mitochondrial genome, ${ }^{1823}$ so that any sizable deletion is bound to include at least one such gene, and hence prevent translation of the remaining mitochondrial genes.

However, the specific distribution of deleted mtDNA among the cells of neuromuscular tissue, ${ }^{29}$ including the degree of heteroplasmy and the possibilities for complementation between wild type and mutant mtDNA, ${ }^{30-32}$ is likely to be decisive for the clinical manifestations in a given patient.

A clinical picture which is completely different from KSS may result when the same mtDNA deletion is predominant in other tissues, as in the Pearson syndrome (PS) ${ }^{6912}$ in which pancytopenia of the blood is associated with exocrine pancreatic dysfunction in early childhood.

Patients who recovered from a crisis of PS in infancy and later developed neuromuscular symptoms leading to the diagnosis of KSS at 7 to 8 years of age have recently been described. ${ }^{89}$ They had heteroplasmy for an mtDNA deletion both in skeletal muscle and in leucocytes. Similarly, in another case of KSS, progressing during early adolescence and associated with a large deletion in a high percentage of muscle mtDNA, a crisis of bone marrow dysfunction had been recorded in early childhood. ${ }^{7}$

The present case is yet another example of a patient who has developed KSS after a transient crisis of bone marrow dysfunction in early childhood, requiring blood transfusion for survival. In such cases heteroplasmy for the mtDNA deletion in question is probably present in various tissues during fetal development and infancy. The clinical manifestations are most probably determined by the percentage of defective mitochondria, in combination with tissue specific thresholds for respiratory chain insufficiency. An increase of deleted mtDNA seems to occur with time in neuromuscular tissue, thus giving rise to KSS, after survival of a possible haematological crisis in early childhood. ${ }^{7}$ The present deletion (fig 6) is different from those previously reported, but is located in the same region of the mtDNA molecule. ${ }^{142032}$ The mechanisms underlying mtDNA deletions are not yet understood, but accumulated evidence stresses the involvement of direct repeats, possibly by allowing either a slippage during $\mathrm{H}$ strand replication or deletion by some kind of unequal crossing over. ${ }^{33-35}$ Recently, a tandem duplication in the mtDNA D loop has been suggested to predispose to such deletions. ${ }^{36}$

In the majority of cases two direct repeats from 5 to $13 \mathrm{bp}$ in length have been detected in the deletion breakpoint regions, one of them always being included in the deletion. ${ }^{2033}$ The 13 bp repeats at positions $8470-8482$ and 13 447-13 459 seem to constitute a mutational hotspot, being involved in the so called common deletion of $4977 \mathrm{bp}$, which accounts for about one-third of all sporadic mtDNA deletions. ${ }^{33} 37$

In the mtDNA of our patient the deletion breakpoints are located in regions where two direct repeats, of 6 and $9 \mathrm{bp}$, are found in the wild type molecule, the former repeat sequence $\mathrm{C}_{5} \mathrm{~T}$ also being part of the latter (fig $6 \mathrm{~B})$. In a replication-slippage model this might allow the formation of a structure with 15 established base pairs as an intermediate in the deletion process.

A computer search shows that the 6 bp sequence $C_{5} T$ is present at 24 locations throughout the wild type mtDNA molecule. This sequence has not been found flanking previously published deletions, hence it seems more likely that the above mentioned $9 \mathrm{bp}$ repeats or a combination of the two are involved in causing the present deletion.

In whites, ${ }^{18}$ as opposed to many Asians, ${ }^{38}$ the $9 \mathrm{bp}$ sequence is present twice as a head to tail duplication at 8271-8288 bp (fig 6B), and one could therefore hypothesise that in the former population this region may be more deletion prone. The fact that this $9 \mathrm{bp}$ repeat is also found at position 8605-8613 suggests the possibility of a deletion involving two of these very closely placed 9 bp repeats. Such a small deletion, comprising only about 325 bp but including the gene for tRNA ${ }^{\text {Lys }}$, would not be detected by routine Southern blot analysis.

It seems obvious that the search for the molecular defect in mtDNA, in cases where a major deletion is not found, should be guided by the accumulated evidence for the involvement of direct repeats and the knowledge of their location in wild type mtDNA.

The densitometric analysis was kindly performed by Dr Finn Cilius Nielsen. The present investigation was supported by The P Carl Petersen Foundation and Øjenfonden (The Eye Foundation under the Danish Association of the Blind) ( $\mathrm{SN}$ ), The Danish Medical Research Council (HS), the Velux Foundation (MW), and 'L'Association Française pour la Lutte contre les Myopathies"' (PL, IN). SN and PL gratefully contre les Myopathies" (PL, IN). SN and PL gratefully
acknowledge collaborative grants from The Danish Ministry of Education and The French Ministry of Foreign Affairs.

1 Kearns TP, Sayre GP. Retinitis pigmentosa, external ophthalmoplegia and complete heart block. Arch Ophthalmol 1958;60:280-9.

2 Berenberg RA, Pellock JM, DiMauro S, et al. Lumping or splitting? 'Ophthalmoplegia-plus' or Kearns-Sayre syndrome? Ann Neurol 1977;1:37-54.

3 Lestienne P, Ponsot G. Kearns-Sayre syndrome with muscle mitochondrial DNA deletion. Lancet 1988;i:885.

4 Mullie MA, Harding AE, Petty RKH, et al. The retinal manifestations of mitochondrial myopathy. A study of 22 manifestations of mitochondrial myopathy. A

5 Pearson HA, Lobel JS, Kocoshis SA, et al. A new syndrome of refractory sideroblastic anemia with vacuolization of marrow precursors and exocrine pancreatic dysfunction. 7 Pediatr 1979;95:976-84.

6 Rötig A, Cormier V, Koll F, et al. Site-specific deletions of the mitochondrial genome in the Pearson marrow-pancreas syndrome. Genomics 1991;10:502-4.

7 Larsson NG, Holme E, Kristiansson B, Oldfors A, Tulinius $M$. Progressive increase of the mutated mitochondrial DNA fraction in Kearns-Sayre syndrome. Pediatr Res 1990;28:131-6.

8 McShane MA, Hammans SR, Sweeney M, et al. Pearson syndrome and mitochondrial encephalomyopathy in patient with a deletion of mtDNA. Am $\mathcal{f}$ Hum Gene 1991;48:39-42.

9 Nelson I, Bonne G, Degoul F, et al. Kearns-Sayre syndrome with sideroblastic anemia: molecular investigations. Neuropediatrics 1992;23:199-205.

10 Holt IJ, Harding AE, Morgan-Hughes JA. Deletions of 
muscle mitochondrial DNA in patients with mitochondrial myopathies. Nature 1988;331:717-19.

11 Zeviani M, Moraes CT, DiMauro S, et al. Deletions of mitochondrial DNA in Kearns-Sayre syndrome. Neurology 1988;38:1339-46.

12 Rötig A, Colonna M, Blanche S, et al. Deletion of blood mitochondrial DNA in pancytopenia. Lancet 1988;ii:5678.

13 Moraes CT, DiMauro S, Zeviani M, et al. Mitochondria DNA deletions in progressive ophthalmoplegia an Kearns-Sayre syndrome. $N$ Engl $\mathcal{Y}$ Med 1989;320:1293-9. 4 Nelson I, Degoul F, Obermaier-Kusser B, et al. Mapping of heteroplasmic mitochondrial DNA deletions in KearnsSayre syndrome. Nucleic Acids Res 1989;17:8117-24.

15 Nørby S, Lestienne P, Nelson I, Nielsen IM, Warburg M. A new deletion in mitochondrial DNA leading to the Kearns-Sayre syndrome. Am $\mathrm{f}$ Hum Genet Suppl 1991;49:207A.

16 Sambrook J, Fritsch EF, Maniatis T. Molecular cloning. A laboratory manual. 2nd ed. New York: Cold Spring Harbor Laboratory Press, 1989.

17 Johns DR, Hurko O. Preferential amplification and molecular characterization of junction sequences of a pathogen1989;5:623-8.

18 Anderson S, Banker AT, Barrell BG, et al. Sequence and organization of the human mitochondrial genome. Nature 1981;290:457-65.

19 Nørby S, Lestienne P, Nelson I, Rosenberg T. Mutation detection in Leber's hereditary optic neuropathy by PCR with allele-specific priming. Biochem Biophys Res Comwith allele-specific p

20 Degoul F, Nelson I, Amselem S, et al. Different mechanisms inferred from sequences of human mitochondrial DNA deletions

21 Lestienne P. Mitochondrial DNA mutations in human disease: a review. Biochimie 1992;74:123-30.

22 Wallace DC. Diseases of the mitochondrial DNA. Annu Rev Biochem 1992;61:1175-212.

23 Shanske S, Moraes CT, Lombes A, et al. Widespread tissue distribution of mitochondrial DNA deletions in KearnsSayre syndrome. Neurology 1990;40:24-8.

24 Lott MT, Voljavec AS, Wallace DC. Variable genotype of Leber's hereditary optic neuropathy patients. Am $\mathcal{F} O p h-$ thalmol 1990;109:625-31.

25 Vilkki J, Savontaus ML, Nikoskelainen EK. Segregation of mitochondrial genomes in a heteroplasmic lineage with Leber hereditary optic neuroretinopathy. Am $7 \mathrm{Hum}$ Genet 1990;47:95-100.

26 Bolhuis PA, Bleeker-Wagemakers EM, Ponne NJ, et al. Rapid shift in genotype of human mitochondrial DNA in a family with Leber's hereditary optic neuropathy. Biochem Biophys Res Commun 1990;170:994-7.

Gerbitz KD, Obermaier-Kusser B, Lestienne P, et al. Mutations of the mitochondrial DNA: the contribution of DNA techniques to the diagnosis of mitochondrial encephalomyopathies. $f$ Clin Chem Clin Biochem 1990;28:241-50.

28 Nakase H, Moraes CT, Rizzuto R, Lombes A, deMauro S, Schon EA. Transcription and translation of deleted mitochondrial genomes in Kearns-Sayre syndrome: implications for pathogenesis. Am $\mathcal{F}$ Hum Genet 1990;46:418-27.

29 Zeviani M, Gellera C, Panacci M, et al. Tissue distribution and transmission of mitochondrial DNA deletions in mitochondrial myopathies. Ann Neurol 1990;28:94-7.

30 Lestienne P. Mitochondrial and nuclear DNA complementation in the respiratory chain function and defects. Biochimie 1989;71:1115-23.

31 Hammans SR, Sweeney MG, Holt IJ, et al. Evidence fo intramitochondrial complementation between deleted and normal mitochondrial DNA in some patients with mitochondrial myopathy. I Neurol Sci 1992;107:87-92.

32 Hayashi JI, Ohta S, Kikuchi A Takemitsu M, Goto YI Nonaka I. Introduction of disease-related mitochondrial DNA deletions into Hela cells lacking mitochondrial DNA deletions into HeLa cells lacking mitochondria Acad Sci USA 1991;88:10614-18.

33 Holt IJ, Harding AE, Morgan-Hughes JA. Deletions of muscle mitochondrial DNA in mitochondrial myopathies: sequence analysis and possible mechanisms. Nucleic ies: sequence analysis and
Acids Res $1989 ; 17: 4465-9$.

34 Mita S, Rizutto R, Moraes CT, et al. Recombination via flanking direct repeats is a major cause of large-scale deletions of human mitochondrial DNA Nucleic Acids Res 1990;18:561-7.

35 Schoffner JM, Lott MT, Voljavec AS, et al. Spontaneous Kearns-Sayre/chronic external ophthalmoplegia plus syndrome associated with a mitochondrial DNA deletion a slip-replication model and metabolic therapy. Proc Nat Acad Sci USA 1989;86:7952-6.

36 Brockington M, Sweeney MG, Hammans SR, MorganHughes JA, Harding AE. A tandem duplication in the Dloop of human mitochondrial DNA is associated with deletions in mitochondrial myopathies. Nature Genet 1993;4:67-71.

37 Schon EA, Rizzuto R, Moraes CT, Nakase H, Zeviani M DiMauro S. A direct repeat is a hotspot for large-scale deletion in human mitochondrial DNA. Science 1989;244:346-9.

38 Hertzberg M, Mickleson KNP, Serjeantson SW, Prior JF, Trent RJ. An Asian-specific 9-bp deletion of mitochonGenet 1989;44:504-10 